\title{
Factors predicting in-breast tumor recurrence after breast-conserving surgery
}

\author{
Robert Mechera · Carsten T. Viehl • \\ Daniel Oertli
}

Received: 4 September 2008/ Accepted: 4 September 2008/Published online: 25 September 2008

(C) Springer Science+Business Media, LLC. 2008

\begin{abstract}
Purpose: The main objectives of this study were to identify risk factors for local in-breast tumor recurrence after breast-conservation and to evaluate the impact of IBTR (in-breast tumor recurrence) on overall survival. Methods: A total of 335 consecutive patients with 346 invasive and in situ breast cancers were treated with breast conserving therapy. Univariate and multivariate statistical analysis were performed and survival rates were calculated and analyzed using the Kaplan-Meier method. Results: With a median follow-up period of 70.6 months 14 patients $(4 \%)$ developed an IBTR. Overall survival and the disease-free 8-year actuarial survival of patients were $95 \%$ and $93 \%$, respectively. The overall survival of patients with tumour recurrence on any site was significantly shorter than of those without recurrence (64\% versus $85 \%$ after 8 years of follow-up; $P<0.0001$ ). Similarly, overall survival was significantly reduced in patients with distant metastases compared to all others without distant disease (88\% versus $40 \%$ after 8 years; $P<0.0001$ ). In contrast, overall survival of patients who experienced IBTR did not differ significantly from the group of patients who never developed IBTR (87\% versus 70\% after 8 years of followup). By univariate analysis, lobular carcinoma, high grade tumours, multifocality, concomitant LCIS and DCIS, the absence of estrogene and progesterone receptor status, as well as R1-status, were significant predictors of IBTR. By multivariate analysis, only $\mathrm{R} 1$-status $(P<0.002)$ and the presence of LCIS around the invasive tumour $(P<0.03)$ remained as significant factors predicting IBTR. Conclusions: Concomitant lobular carcinomas in situ, as well as
\end{abstract}

R. Mechera $\cdot$ C. T. Viehl $\cdot$ D. Oertli $(\bowtie)$

Department of Surgery, University Hospital Basel,

Spitalstrasse 21, 4031 Basel, Switzerland

e-mail: doertli@uhbs.ch
R1 surgical status are independent significant risk factors for in breast tumor recurrence after breast conserving therapy.

Keywords Breast neoplasms - Surgery ·

Breast conservation - Tumour recurrence - Survival .

Radiotherapy

\section{Introduction}

Surgical therapy for breast cancer has significantly developed over the past three decades. During the 1970s, Fisher in New York and Veronesi in Milano, Italy, revolutionized the surgical treatment with the paradigm shift from the standard modified radical mastectomy towards breast conservation (i.e. lumpectomy and adjuvant radiotherapy). The results of two large randomized controlled series have firmly established the principle of breast conservation being equally safe and effective as mastectomy for the majority of patients with stage I and II disease [1, 2], while achieving cosmetically superior results. Moreover, 20 and 25-year follow-up series for breast conserving therapy have further confirmed that, compared to mastectomy, breast conserving therapy (BCT) achieved an identical survival rate $[3,4]$.

During breast conservation (also known as lumpectomy, segmental mastectomy or wide local excision), the tumor is removed with a disease free margin. Although the minimal size of tumor free resection margin is not definitively identified, there is compelling evidence that positive resection margins lead to an increased rate of local inbreast recurrence [5-7].

Two etiologic types of ipsilateral, so-called in-breast tumor recurrence (IBTR) exist:(i) True local recurrences develop from cancer cells that have not been completely 
removed during surgery; (ii) new primary tumors are defined as new cancers arising from the residual ipsilateral breast parenchyma [8].

Adjuvant percutaneous radiation therapy significantly reduces the rate of local recurrences, and data from this overview published in 2002 indicate that the addition of radiation therapy also improves overall survival [9].

While radiotherapy clearly reduces the rate of IBTR, the following factors have been attributed to increase the risk of IBTR: Young age at the time of primary therapy [10, 11], high tumor grade [12-15], specific histological types, for example concomitant LCIS [16], lympho-vascular invasion $[10,12-15,17]$, extensive intraductal component (EIC) [10, $13,14,17-20]$ and the lack of adjuvant systemic therapy like hormone- and chemotherapy [1,21]. Concerning EIC, two main studies have demonstrated, that providing clear margins, there is no increased rate of local recurrence in patients with EIC [5, 6].

The objective of our study was to analyze a prospectively maintained database for factors influencing postoperative IBTR and survival.

\section{Materials and methods}

Between January 1990 and December 2004, 335 patients with 346 invasive and in situ breast cancers were treated with breast conserving therapy at the Department of Surgery, University Hospital Basel. All patient's data have prospectively been entered into a computerized database. Bilateral tumors were observed in 11 patients (3.3\%). At the time of diagnosis, the patients had a median age of 54.2 years (range $41.5-81.3$ years).

The surgical procedure consisted of a quadrantectomy or lumpectomy with axillary nodal staging for invasive cancers. Axillary lymph node dissection of level 1 and 2 was performed during the first study period until 1998. In 1999, sentinel lymph node procedure was introduced at the University Hospital Basel [22]. After a validation period, standard axillary lymph node dissection was only performed if macrometastases were found in the excised sentinel lymph node or when the sentinel lymph node could not reliably be identified.

Adjuvant chemotherapy or hormonal therapy was performed according to the newest St. Gallen consensus available at the time of treatment [23]. Generally, patients with advanced stage carcinomas were offered an adjuvant chemotherapy, neoadjuvant chemotherapy or in selected cases both of them.

The majority of patients (82.6\%) underwent adjuvant radiation therapy to the breast; 4 Patients $(1.2 \%)$ were treated in a neoadjuvant setting by breast irradiation; 54 patients did not receive radiation; this either because of denial from the patient or histological subtypes. Radiation therapy was administered with a total dose of 50.4 Gy to the whole breast $(5 \times 1.8$ Gy weekly). Patients younger than 60 years with $\mathrm{R} 0$ excision received an additional boost dose of $10 \mathrm{~Gy}(5 \times 2$ Gy for one week) to the tumor bed. Patients with close margins $(<3 \mathrm{~mm})$ received a boost dose of 20 Gy $(5 \times 2$ Gy weekly) to the tumor bed irrespective of age. Patients older than 60 years with R0 excision received no additional boost dose on contrary to patients with close margins $(<3 \mathrm{~mm})$ excision who received a boost dose of 20 Gy $(5 \times 2$ Gy weekly). Boost doses were only applied to the tumor bed. Radiation therapy to the whole breast was administered using photons, and to the tumor bed using electrons.

In order to classify also the tumors with skin infiltration according to latest standards, the new TNM classification was used [24].

This study has been approved by the regional Ethical Committee responsible for the University Hospital Basel.

Statistical analysis was performed with the STATISTICA software package (Statsoft Inc. Tulsa, Oklahoma, U.S.A.). The Mann-Whitney- $U$ test was used for univariate analysis of continuous variables when comparing two independent groups, and the chi-squared test for $2 \times 2$ categorical tables. Clinical and pathological factors that have been tested significantly by univariate analysis underwent multivariate analysis using the Cox regression model. Survival curves were calculated according to the Kaplan-Meier life-table method with differences in survival curves tested by the log-rank test. Patient's characteristics are listed and described in Table 1.

\section{Results}

Median follow-up was 70.6 months (range 7-190 months). 11 out of 346 patients (3.2\%) suffered from distant metastases and $14(4.0 \%)$ had developed IBTR. The overall survival and the disease-free 8-year actuarial survival of patients were $95 \%$ and $93 \%$, respectively (Fig. 1).

The overall survival of patients with tumour recurrence on any site was significantly shorter than of those without recurrence (64\% versus $85 \%$ after 8 years of follow-up; $P<0.0001$; Fig. 2). Similarly, overall survival was significantly reduced in patients with distant metastases compared to all other patients without distant disease (88\% versus $40 \%$ after 8 years; $P<0.0001$; Fig. 3 ). In contrast, overall survival of patients who experienced IBTR did not differ significantly from the group of patients who never developed IBTR (87\% versus $70 \% 8$ years of follow-up), as shown in Fig. 4.

By univariate analysis, lobular carcinoma, high grade tumours, multifocality, concomitant LCIS and DCIS, the 
Table 1 Cases characteristics $(N=346)$

\begin{tabular}{|c|c|c|}
\hline Characteristics & No. & $\%$ \\
\hline \multicolumn{3}{|l|}{ Age group (years) } \\
\hline \multicolumn{3}{|l|}{ Median age } \\
\hline $20-40$ & 24 & 6.9 \\
\hline $40-60$ & 161 & 46.5 \\
\hline $60-80$ & 149 & 43.1 \\
\hline$>80$ & 12 & 3.5 \\
\hline \multicolumn{3}{|l|}{ Staging } \\
\hline $\mathrm{T} 1$ & 210 & 60.7 \\
\hline $\mathrm{T} 2$ & 97 & 28.0 \\
\hline $\mathrm{T} 3$ & 1 & 0.3 \\
\hline $\mathrm{T} 4$ & 6 & 1.7 \\
\hline Tis & 28 & 8.1 \\
\hline Unknown & 4 & 1.2 \\
\hline \multicolumn{3}{|l|}{ Node status } \\
\hline No & 249 & 71.9 \\
\hline N1 & 71 & 20.5 \\
\hline $\mathrm{N} 2$ & 10 & 2.9 \\
\hline N3 & 3 & 0.9 \\
\hline $\mathrm{NX}$ & 10 & 2.9 \\
\hline Unknown & 3 & 0.9 \\
\hline \multicolumn{3}{|l|}{ M status } \\
\hline M0 & 331 & 95.7 \\
\hline M1 & 1 & 0.3 \\
\hline $\mathrm{Mx}$ & 13 & 3.6 \\
\hline Unknown & 1 & 0.4 \\
\hline \multicolumn{3}{|l|}{ Grading } \\
\hline G1 & 75 & 21.7 \\
\hline $\mathrm{G} 2$ & 151 & 43.6 \\
\hline G3 & 98 & 28.3 \\
\hline Unknown & 22 & 6.4 \\
\hline \multicolumn{3}{|l|}{ Histopathological type } \\
\hline Invasive ductal & 233 & 67.3 \\
\hline Invasive lobular & 37 & 10.7 \\
\hline Tubular & 19 & 5.5 \\
\hline Mucinous & 10 & 2.9 \\
\hline Medullary & 10 & 2.9 \\
\hline Invasive ductulolobular & 8 & 2.3 \\
\hline Non invasive Adenoca & 29 & 8.4 \\
\hline \multicolumn{3}{|c|}{ R-status (including peritumoral DCIS) } \\
\hline $\mathrm{R} 0$ & 320 & 92.5 \\
\hline $\mathrm{R} 1$ & 25 & 7.2 \\
\hline $\mathrm{R} 2$ & 1 & 0.3 \\
\hline \multicolumn{3}{|l|}{ Lymphovascular invasion } \\
\hline Yes & 79 & 22.8 \\
\hline No & 265 & 76.6 \\
\hline Unknown & 2 & 0.6 \\
\hline
\end{tabular}

Table 1 continued

\begin{tabular}{|c|c|c|}
\hline Characteristics & No. & $\%$ \\
\hline \multicolumn{3}{|c|}{ Extensive intraductal component } \\
\hline Yes & 24 & 6.9 \\
\hline No & 310 & 89.6 \\
\hline Unknown & 12 & 3.5 \\
\hline \multicolumn{3}{|l|}{ Localisation } \\
\hline Left breast & 181 & 52.3 \\
\hline Right breast & 165 & 47.7 \\
\hline \multicolumn{3}{|l|}{ Axillary dissection } \\
\hline Yes & 201 & 58.1 \\
\hline No & 137 & 39.6 \\
\hline Unknown & 8 & 2.3 \\
\hline \multicolumn{3}{|l|}{ ER status } \\
\hline Yes & 264 & 76.3 \\
\hline No & 54 & 15.6 \\
\hline Unknown & 28 & 8.1 \\
\hline \multicolumn{3}{|l|}{ PR status } \\
\hline Yes & 222 & 64.2 \\
\hline No & 100 & 28.9 \\
\hline Unknown & 24 & 6.9 \\
\hline \multicolumn{3}{|l|}{ Hormone therapy } \\
\hline Yes & 240 & 69.4 \\
\hline No & 87 & 25.1 \\
\hline Unknown & 19 & 5.5 \\
\hline \multicolumn{3}{|l|}{ Chemotherapy } \\
\hline Neoadjuvant & 3 & 0.9 \\
\hline Adjuvant & 60 & 17.3 \\
\hline Neoadjuvant + Adjuvant & 2 & 0.6 \\
\hline No & 280 & 80.9 \\
\hline Unknown & 1 & 0.3 \\
\hline \multicolumn{3}{|l|}{ Radiotherapy } \\
\hline Neoadjuvant & 4 & 1.2 \\
\hline Adjuvant & 288 & 83.2 \\
\hline No & 54 & 15.6 \\
\hline
\end{tabular}

absence of estrogene and progesterone receptor status, as well as R1-status, were significant predictors of IBTR. In contrast, nodal status was not a predictive factor for IBTR (Tables 2, 3).

By multivariate analysis, the R1-status $(P<0.002)$ and the presence of LCIS around the invasive tumour $(P<0.03)$ remained as significant factors predicting IBTR (Table 4).

The treatment of IBTR consisted of mastectomies ( 9 out of 14) or yet another breast conservation (4 out of 14). Due to denial of therapy, one patient's IBTR was not treated at 


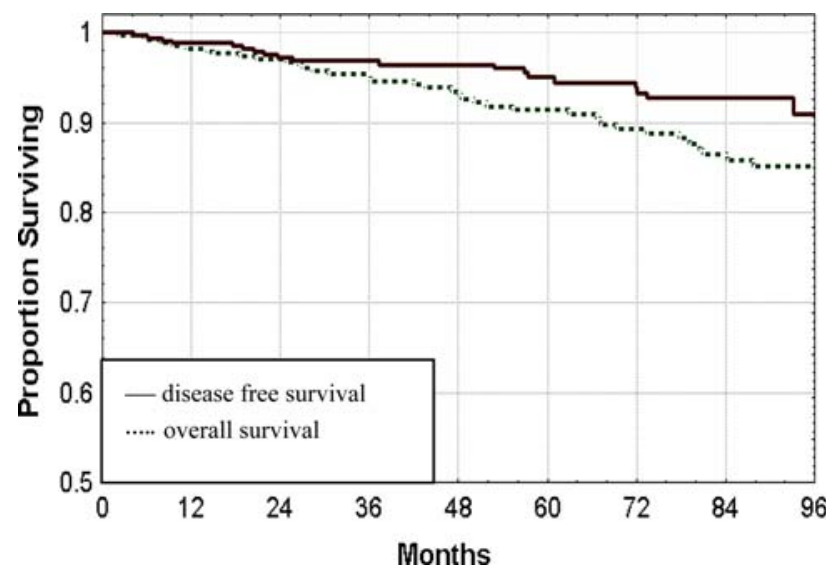

Fig. 1 Overall survival and the disease-free actuarial survival

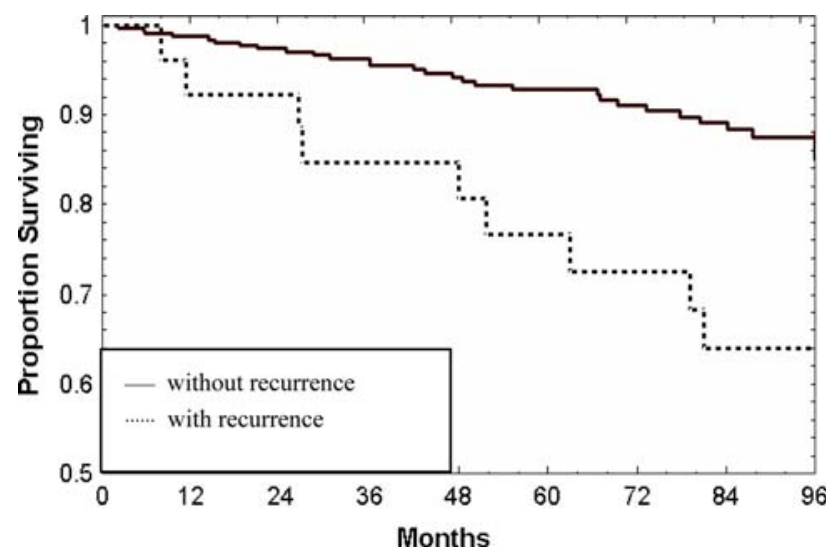

Fig. 2 Overall survival of patients with tumour recurrence on any site and without recurrence

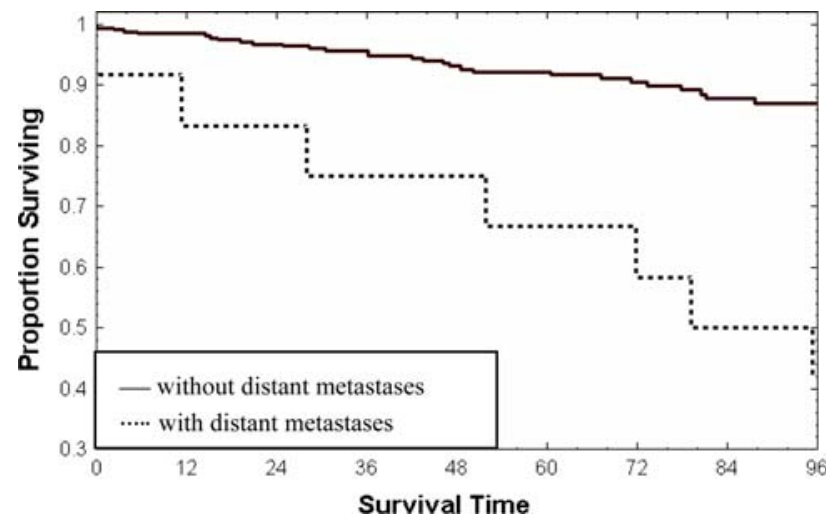

Fig. 3 Overall survival in patients with distant metastases and all other patients without distant disease

all. In both groups, mastectomies and breast conservation, one second recurrence has been reported. The pattern of all recurrences is demonstrated in Table 5 and the course of disease of patients with IBTR is shown in Table 6.

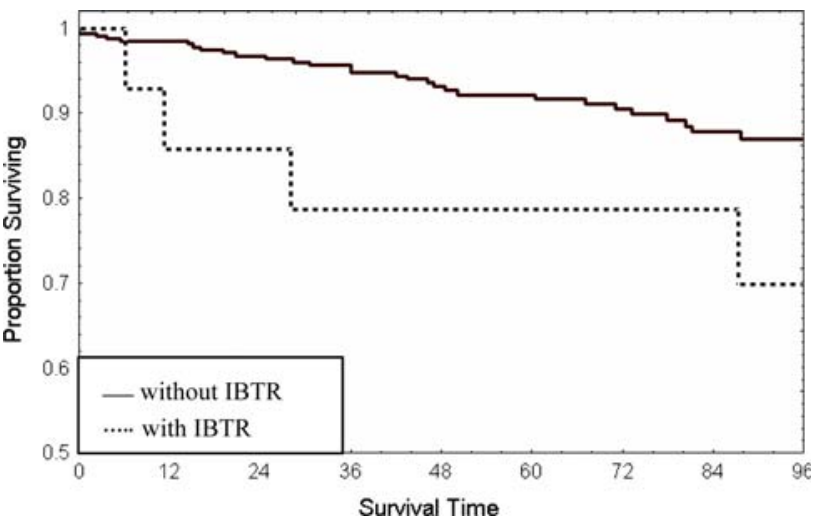

Fig. 4 Overall survival of patients with IBTR and without IBTR

\section{Discussion}

Since Fisher [1] and Veronesi [2] have established the equality in outcome of breast-conserving surgery followed by radiation therapy compared to modified radical mastectomy, BCT has become standard of care for early breast cancer. The search for identification of relevant risk factors for local tumor relapse (i.e. IBTR) has widely been made but is still ongoing. The purpose of this study was to explore a prospectively maintained database of 346 consecutive patients with primary breast cancer undergoing BCT from 1990 to 2004 at the Department of Surgery, University Hospital Basel, and to examine potential risk factors for IBTR and their prognostic influence on patient's overall survival and also to compare them with published material.

In the current study we used an univariate and a multivariate analysis of the collected data material in order to detect factors predicting for the occurrence of IBTR. We found that several significant tumor characteristics were predictive for IBTR including lobular carcinoma, high tumor grade, R1-status, absence of estrogene and progesterone receptors and concomitant LCIS and DCIS using the univariate analysis. Multivariate analysis revealed that only concomitant LCIS and positive microscopic margins (R1status) remained independent predictors of IBTR.

IBTR rate was $4 \%$ after a median follow-up of 70.6 months in our study. The previously reported percentage of IBTR varies from $1.3 \%$ [25] to $8.5 \%$ [26]. Cabioglu et al. [25], explain their low number (IBTR rate $1.3 \%$ ) with a decrease of IBTR in patients $<50$ years within a specific time range in their observation period. In our study we couldn't find a lower incidence of IBTR in younger patients. We therefore assume it to be the reason for our higher IBTR rate.

Komoike et al. [26] reported patients treated before 1993 and described a $8.5 \%$ rate of IBTR within a median follow-up period of 107 months. This is a considerable longer median follow up compared to our study 
Table 2 Analysed categorical factors according to in-breast tumour recurrence

\begin{tabular}{|c|c|c|c|c|c|c|}
\hline \multirow{2}{*}{\multicolumn{2}{|c|}{ Factors }} & \multicolumn{2}{|c|}{$\operatorname{IBTR}(n=14)$} & \multicolumn{2}{|c|}{ No IBTR $(n=332)$} & \multirow{2}{*}{$\begin{array}{l}\text { Statistical } \\
\text { significance }\end{array}$} \\
\hline & & $N$ & $\%$ & $N$ & $\%$ & \\
\hline \multicolumn{7}{|l|}{ Histology } \\
\hline \multicolumn{2}{|l|}{ Lobular carcinoma } & 4 & 29 & 33 & 9.9 & $P<0.03$ \\
\hline \multicolumn{2}{|l|}{ All other carcinomas } & 10 & 71 & 299 & 91.1 & \\
\hline \multicolumn{7}{|l|}{ Grading } \\
\hline \multicolumn{2}{|l|}{ G1 and G2 } & 8 & 57 & 331 & 99.7 & $P<0.0001$ \\
\hline \multicolumn{2}{|l|}{ G3 } & 6 & 43 & 1 & 0.3 & \\
\hline \multicolumn{7}{|l|}{ Multifocality } \\
\hline \multicolumn{2}{|l|}{ Yes } & 4 & 29 & 25 & 7.5 & $P<0.02$ \\
\hline \multicolumn{2}{|l|}{ No } & 10 & 71 & 307 & 92.5 & \\
\hline \multicolumn{7}{|c|}{ Concomitant in situ carcinoma } \\
\hline \multicolumn{2}{|l|}{ DCIS } & 11 & 89 & 151 & 45.5 & $P<0.02$ \\
\hline \multicolumn{2}{|l|}{ No DCIS } & 3 & 21 & 181 & 54.5 & \\
\hline \multicolumn{2}{|l|}{ LCIS } & 4 & 29 & 17 & 5.1 & $P<0.0001$ \\
\hline \multicolumn{2}{|l|}{ No LCIS } & 10 & 71 & 315 & 94.9 & \\
\hline \multicolumn{7}{|l|}{ Receptor status } \\
\hline \multirow[t]{2}{*}{ Estrogene } & Positive & 8 & 57 & 266 & 80.1 & $P<0.02$ \\
\hline & Negative & 6 & 43 & 66 & 19.9 & \\
\hline \multirow[t]{2}{*}{ Progesterone } & Positive & 5 & 36 & 236 & 71.1 & $P<0.01$ \\
\hline & Negative & 9 & 64 & 96 & 28.9 & \\
\hline \multicolumn{7}{|l|}{ Margin status } \\
\hline \multicolumn{2}{|l|}{ R 0} & 11 & 89 & 310 & 93.4 & $P<0.04$ \\
\hline \multicolumn{2}{|l|}{ R 1} & 3 & 21 & 22 & 6.6 & \\
\hline \multicolumn{7}{|l|}{ Nodal status } \\
\hline \multicolumn{2}{|l|}{ No } & 11 & 89 & 238 & 80.8 & N.S. \\
\hline \multicolumn{2}{|l|}{$\mathrm{N}+$} & 3 & 21 & 64 & 19.2 & \\
\hline
\end{tabular}

Table 3 Analysed non-parametric factors according to in-breast tumour recurrence

\begin{tabular}{|c|c|c|c|c|c|}
\hline \multirow[t]{2}{*}{ Factors } & \multicolumn{2}{|c|}{ IBTR } & \multicolumn{2}{|c|}{ No IBTR } & \multirow[t]{2}{*}{ Significance } \\
\hline & \multicolumn{2}{|c|}{ Median (Min; Max) } & \multicolumn{2}{|c|}{ Median (Min; Max) } & \\
\hline Patient age at operation (years) & 54 & $(41.5 ; 81.3)$ & 59 & $(29.7 ; 92.8)$ & N.S. \\
\hline Tumour diameter (mm) & 21.7 & $(20 ; 48)$ & 16.0 & $(1 ; 73)$ & N.S. \\
\hline Resection margin (mm) & 3.5 & $(<1 ; 8)$ & 2.0 & $(<1 ; 25)$ & N.S. \\
\hline
\end{tabular}

Table 4 Results from multivariate analysis

\begin{tabular}{ll}
\hline Variable & $P$ value \\
\hline EIC & 0.65 \\
Resection margin & 0.47 \\
Tumor size & 0.24 \\
Tumor grading & 0.47 \\
R-status & 0.001 \\
Nodal-status & 0.07 \\
Multifocality & 0.71 \\
Concomitant DCIS & 0.36 \\
Concomitant LCIS & 0.025 \\
Positive ER-status & 0.29 \\
Positive PR-status & 0.41 \\
\hline
\end{tabular}

Table 5 Anatomic distribution of tumour recurrence

\begin{tabular}{lllrl}
\hline Recurrence & & $\begin{array}{l}\text { Lymph } \\
\text { node }\end{array}$ & IBTR & $\begin{array}{l}\text { Distant } \\
\text { metastases }\end{array}$ \\
\hline Lymph node & $4(1.2)$ & 2 & 1 & 1 \\
IBTR & $14(4.0)$ & 1 & 11 & 2 \\
Distant metastases & $11(3.1)$ & 1 & 2 & 8 \\
Total & $27(7.8)$ & 4 & 14 & 11 \\
\hline
\end{tabular}

(70.6 months). Another study [27] matching well the median follow-up in Komoike's work is reporting an IBTR rate of $7.5 \%$. They observed their patients until 1993 with a follow up period of 103.2 month. Nottage et al. [28] reported an IBTR rate of $6 \%$ after a follow-up of 
Table 6 Course of disease after IBTR

\begin{tabular}{|c|c|c|c|c|c|c|}
\hline Nr. & $\begin{array}{l}\text { Interval to } \\
\text { IBTR } \\
\text { (months) }\end{array}$ & Therapy & $\begin{array}{l}\text { Interval from } 1 \text { st } \\
\text { to } 2 \text { nd recurrence } \\
\text { (months) }\end{array}$ & Therapy & Alive & $\begin{array}{l}\text { Year of } \\
\text { death }\end{array}$ \\
\hline 1 & 18 & Lumpectomy $+\mathrm{AD}$ & 125 (IBTR) & Mastectomy & $\mathrm{X}$ & \\
\hline 2 & 20 & Mastectomy & 24 (Scar) & Tumorectomy $+\mathrm{RT}$ & $\mathrm{X}$ & \\
\hline 3 & 49 & Mastectomy & & & $\mathrm{X}$ & \\
\hline 4 & $4 *$ & Mastectomy & & & & 1999 \\
\hline 5 & 97 & Mastectomy + AHT & & & & 2006 \\
\hline 6 & $9 *$ & Mastectomy + AHT & & & & 2005 \\
\hline 7 & 72 & Mastectomy + AHT & & & $\mathrm{X}$ & \\
\hline 8 & 73 & Tumorectomy & 40 (Bones and Pleura) & & $X$ & \\
\hline 9 & 26 & Mastectomy & & & $\mathrm{X}$ & \\
\hline 10 & 152 & Mastectomy & & & $\mathrm{X}$ & \\
\hline 11 & 6 & No therapy & & & & 1996 \\
\hline 12 & 110 & Tumorectomy + HT & & & $\mathrm{X}$ & \\
\hline 13 & 20 & Mastectomy $+\mathrm{NCT}+\mathrm{ACT}+\mathrm{NRT}$ & & & & 2002 \\
\hline 14 & 57 & Lumpectomy & & & $X$ & \\
\hline
\end{tabular}

*, additional distant metastases; AD, axillary dissection; NCT, neoadjuvant chemotherapy; ACT, adjuvant chemotherapy; AHT, adjuvant hormone therapy; DM, distant metastases; NRT, neoadjuvant radiotherapy

130.8 months but they included patients only with free margins in their study. Compared to our study, the higher median follow up periods and the time period where the patients were treated, may have caused the higher reported IBTR rates in these three studies.

One publication is closer to our study setting and may display a better comparison: The work of Elder et al. [29], who also observed a similar period of time, found a IBTR rate of $4.9 \%$ with a follow up time of 48 months.

Probably due to the limited number of patients in our study, we could not demonstrate a statistically significant association of IBTR with poorer overall survival, as has been demonstrated by Fortin et al. [30].

One of the most important factors influencing the risk for IBTR is the pathologic margin status after BCT [31]. Positive surgical margins seem to be relevant predictors for systemic recurrence as well [32]. In our study we could confirm that R1 resection was a statistically significant predictor of IBTR. Of note, the resection margin in the cases with IBTR was rather wider than in cases without IBTR. This demonstrates, that adequate excision of the tumor was accomplished and that the margins chosen, had probably no impact on IBTR in our patients.

Although no clear guidelines concerning re-resection of breast tissue have been determined, common practice aims today at achieving microscopically free margins of more than $1 \mathrm{~mm}$ [6].

More controversial than the R-status is the influence of concomitant LCIS around the invasive tumor. As opposed to Abner et al. [33] who have shown no significant difference between patients with concomitant LCIS in the tumor bed and without, we could elucidate that presence of LCIS has a significant influence on IBTR. Therefore, LCIS when present with invasive breast cancer should carefully be controlled during follow up. In addition, the impact of other adjuvant modalities such as hormonal therapy in the management of LCIS should be discussed as suggested by Fisher et al. [16]. This theory is also confirmed by the work of Jolly et al. [34], whose conclusion is, that LCIS may have significant premalignant potential and progress to an invasive IBTR at the site of index lesion.

Although several studies in the past have shown young age as a significant risk factor for IBTR [11] we could only show a trend towards this direction. We assume that the smaller number of cases in the present study, compared to Elkhuizen's [11], might be a relevant reason for that.

In conclusion, with an observed IBTR rate of $4 \%$ our results lay within the frequency range of IBTR in published data. Moreover, we could implement that the impact of concomitant LCIS and R1-margins are independent predictors for IBTR.

\section{References}

1. Fisher B, Redmond C, Poisson R et al (1989) Eight-year results of a randomized clinical trial comparing total mastectomy and lumpectomy with or without irradiation in the treatment of breast cancer. N Engl J Med 320(13):822-828

2. Veronesi U, Salvadori B, Luini A et al (1990) Conservative treatment of early breast cancer. Long-term results of 1232 cases treated with quadrantectomy, axillary dissection, and radiotherapy. Ann Surg 211(3):250-259

3. Fisher B, Jeong JH, Anderson S, Bryant J, Fisher ER, Wolmark N (2002) Twenty-five-year follow-up of a randomized trial 
comparing radical mastectomy, total mastectomy, and total mastectomy followed by irradiation. N Engl J Med 347(8):567575. doi:10.1056/NEJMoa020128

4. Veronesi U, Cascinelli N, Mariani L et al (2002) Twenty-year follow-up of a randomized study comparing breast-conserving surgery with radical mastectomy for early breast cancer. N Engl J Med 347(16):1227-1232. doi:10.1056/NEJMoa020989

5. Gage I, Schnitt SJ, Nixon AJ et al (1996) Pathologic margin involvement and the risk of recurrence in patients treated with breastconserving therapy 13. Cancer 78(9):1921-1928. doi:10.1002/(SICI) 1097-0142(19961101)78:9<1921::AID-CNCR12>3.0.CO;2-\#

6. Smitt MC, Nowels KW, Zdeblick MJ et al (1995) The importance of the lumpectomy surgical margin status in long-term results of breast conservation. Cancer 76(2):259-267. doi:10.1002/10970142(19950715)76:2<259::AID-CNCR2820760216>3.0.CO;2-2

7. Wazer DE, Jabro G, Ruthazer R, Schmid C, Safaii H, SchmidtUllrich RK (1999) Extent of margin positivity as a predictor for local recurrence after breast conserving irradiation. Radiat Oncol Investig 7(2):111-117. doi:10.1002/(SICI)1520-6823(1999)7: 2<111::AID-ROI7>3.0.CO;2-U

8. Huang E, Buchholz TA, Meric F et al (2002) Classifying local disease recurrences after breast conservation therapy based on location and histology: new primary tumors have more favorable outcomes than true local disease recurrences. Cancer 95(10):2059-2067. doi:10.1002/cncr.10952

9. Dixon JM, Gregory K, Johnston S, Rodger A (2002) Breast cancer: non-metastatic. Clin Evid 8:1811-1839

10. Kurtz JM (1992) Factors influencing the risk of local recurrence in the breast. Eur J Cancer 28(2-3):660-666. doi:10.1016/ S0959-8049(05)80121-2

11. Elkhuizen PH, van Slooten HJ, Clahsen PC et al (2000) High local recurrence risk after breast-conserving therapy in nodenegative premenopausal breast cancer patients is greatly reduced by one course of perioperative chemotherapy: a European Organization for Research and Treatment of Cancer Breast Cancer Cooperative Group Study. J Clin Oncol 18(5):1075-1083

12. Locker AP, Ellis IO, Morgan DA, Elston CW, Mitchell A, Blamey RW (1989) Factors influencing local recurrence after excision and radiotherapy for primary breast cancer. Br J Surg 76(9):890-894. doi:10.1002/bjs.1800760906

13. Kurtz JM, Jacquemier J, Amalric R et al (1990) Risk factors for breast recurrence in premenopausal and postmenopausal patients with ductal cancers treated by conservation therapy. Cancer 65(8):1867-1878. doi:10.1002/1097-0142(19900415)65:8<1867::AID-CNCR282065 0833>3.0.CO;2-I

14. Lindley R, Bulman A, Parsons P, Phillips R, Henry K, Ellis H (1989) Histologic features predictive of an increased risk of early local recurrence after treatment of breast cancer by local tumor excision and radical radiotherapy. Surgery 105(1):13-20

15. Clarke DH, Le MG, Sarrazin D et al (1985) Analysis of localregional relapses in patients with early breast cancers treated by excision and radiotherapy: experience of the Institut GustaveRoussy. Int J Radiat Oncol Biol Phys 11(1):137-145

16. Fisher ER, Land SR, Fisher B, Mamounas E, Gilarski L, Wolmark N (2004) Pathologic findings from the National Surgical Adjuvant Breast and Bowel Project: twelve-year observations concerning lobular carcinoma in situ. Cancer 100(2):238-244. doi:10.1002/cncr.11883

17. Fourquet A, Campana F, Zafrani B et al (1989) Prognostic factors of breast recurrence in the conservative management of early breast cancer: a 25-year follow-up. Int J Radiat Oncol Biol Phys 17(4):719-725

18. Boyages J, Recht A, Connolly J et al (1989) Factors associated with local recurrence as a first site of failure following the conservative treatment of early breast cancer. Recent Results Cancer Res 115:92-102
19. Eberlein TJ, Connolly JL, Schnitt SJ, Recht A, Osteen RT, Harris JR (1990) Predictors of local recurrence following conservative breast surgery and radiation therapy. The influence of tumor size. Arch Surg 125(6):771-775

20. Jacquemier J, Kurtz JM, Amalric R, Brandone H, Ayme Y, Spitalier JM (1990) An assessment of extensive intraductal component as a risk factor for local recurrence after breastconserving therapy. Br J Cancer 61(6):873-876

21. Rose MA, Henderson IC, Gelman R et al (1989) Premenopausal breast cancer patients treated with conservative surgery, radiotherapy and adjuvant chemotherapy have a low risk of local failure. Int J Radiat Oncol Biol Phys 17(4):711-717

22. Langer I, Marti WR, Guller U et al (2005) Axillary recurrence rate in breast cancer patients with negative sentinel lymph node (SLN) or SLN micrometastases: prospective analysis of 150 patients after SLN biopsy. Ann Surg 241(1):152-158

23. Goldhirsch A, Wood WC, Gelber RD, Coates AS, Thurlimann B, Senn HJ (2007) Progress and promise: highlights of the international expert consensus on the primary therapy of early breast cancer 2007. Ann Oncol 18(7):1133-1144. doi:10.1093/annonc/mdm271

24. Guth U, Singer G, Langer I et al (2006) T4 category revision enhances the accuracy and significance of stage III breast cancer. Cancer 106(12):2569-2575. doi:10.1002/cncr.21920

25. Cabioglu N, Hunt KK, Buchholz TA et al (2005) Improving local control with breast-conserving therapy: a 27 -year single-institution experience 19. Cancer 104(1):20-29. doi:10.1002/cncr.21121

26. Komoike Y, Akiyama F, Iino $Y$ et al (2006) Ipsilateral breast tumor recurrence (IBTR) after breast-conserving treatment for early breast cancer: risk factors and impact on distant metastases. Cancer 106(1):35-41. doi:10.1002/cncr.21551

27. Haffty BG, Reiss M, Beinfield M, Fischer D, Ward B, McKhann C (1996) Ipsilateral breast tumor recurrence as a predictor of distant disease: implications for systemic therapy at the time of local relapse. J Clin Oncol 14(1):52-57

28. Nottage MK, Kopciuk KA, Tzontcheva A, Andrulis IL, Bull SB, Blackstein ME (2006) Analysis of incidence and prognostic factors for ipsilateral breast tumour recurrence and its impact on disease-specific survival of women with node-negative breast cancer: a prospective cohort study. Breast Cancer Res 8(4):R44. doi:10.1186/bcr1531

29. Elder EE, Kennedy CW, Gluch L et al (2006) Patterns of breast cancer relapse. Eur J Surg Oncol 32(9):922-927. doi:10.1016/ j.ejso.2006.06.001

30. Fortin A, Larochelle M, Laverdiere J, Lavertu S, Tremblay D (1999) Local failure is responsible for the decrease in survival for patients with breast cancer treated with conservative surgery and postoperative radiotherapy. J Clin Oncol 17(1):101-109

31. Park CC, Mitsumori M, Nixon A et al (2000) Outcome at 8 years after breast-conserving surgery and radiation therapy for invasive breast cancer: influence of margin status and systemic therapy on local recurrence 21. J Clin Oncol 18(8):1668-1675

32. Meric F, Mirza NQ, Vlastos G et al (2003) Positive surgical margins and ipsilateral breast tumor recurrence predict diseasespecific survival after breast-conserving therapy. Cancer 97(4): 926-933. doi:10.1002/cncr.11222

33. Abner AL, Connolly JL, Recht A et al (2000) The relation between the presence and extent of lobular carcinoma in situ and the risk of local recurrence for patients with infiltrating carcinoma of the breast treated with conservative surgery and radiation therapy. Cancer 88(5):1072-1077. doi:10.1002/(SICI)1097-0142 (20000301)88:5<1072::AID-CNCR18>3.0.CO;2-D

34. Jolly S, Kestin LL, Goldstein NS, Vicini FA (2006) The impact of lobular carcinoma in situ in association with invasive breast cancer on the rate of local recurrence in patients with early-stage breast cancer treated with breast-conserving therapy. Int J Radiat Oncol Biol Phys 66(2):365-371. doi:10.1016/j.ijrobp.2006.05.070 